\title{
Modelling of monsoon rainfall for a mesoscale catchment in North-West India I: assessment of objective circulation patterns
}

\author{
E. Zehe ${ }^{1}$, A. K. Singh ${ }^{2}$, and A. Bárdossy ${ }^{3}$ \\ ${ }^{1}$ Institute of Geoecology, University of Potsdam, Germany \\ ${ }^{2}$ Civil Engineering Department, Nirma University of Science \& Technology (NU) Ahmedabad - 382 481, India \\ ${ }^{3}$ Institute of Hydraulic Engineering, University of Stuttgart, Germany
}

Received: 15 July 2005 - Published in Hydrol. Earth Syst. Sci. Discuss.: 20 September 2005

Revised: 24 May 2006 - Accepted: 24 October 2006 - Published: 30 October 2006

\begin{abstract}
Within the present study we shed light on the question whether objective circulation patterns (CP) classified from either the $500 \mathrm{HPa}$ or the $700 \mathrm{HPa}$ level may serve as predictors to explain the spatio-temporal variability of monsoon rainfall in the Anas catchment in North West India. To this end we employ a fuzzy ruled based classification approach in combination with a novel objective function as originally proposed by (Stehlik and Brdossy, 2002). After the optimisation we compare the obtained circulation classification schemes for the two pressure levels with respect to their conditional rainfall probabilities and amounts. The classification scheme for the $500 \mathrm{HPa}$ level turns out to be much more suitable to separate dry from wet meteorological conditions during the monsoon season. As is shown during a bootstrap test, the $\mathrm{CP}$ conditional rainfall probabilities for the wet and the dry CPs for both pressure levels are highly significant at levels ranging from 95 to $99 \%$. Furthermore, the monthly $\mathrm{CP}$ frequencies of the wettest CPs show a significant positive correlation with the variation of the total number of rainy days at the monthly scale. Consistently, the monthly frequencies of the dry CPs exhibit a negative correlation with the number of rainy days at the monthly scale. The present results give clear evidence that the circulation patterns from the $500 \mathrm{HPa}$ level are suitable predictors for explaining spatio- temporal Monsoon variability. A companion paper shows that the $\mathrm{CP}$ time series obtained within this study are suitable input into a stochastical rainfall model.
\end{abstract}

\section{Introduction}

The strong seasonality of the Indian climate and especially the onset and strength of the rainy season determines to a high degree the socio-economic development and agricul-

Correspondence to: E. Zehe

(ezehe@rz.uni-potsdam.de) tural productivity of India's arid and semi-arid regions, which comprise more than $50 \%$ of its land area (MoE, 2004). With $2 / 3$ of the Indian population depending on agriculture for employment and $2 / 3$ of the cultivated land relying on rainfed farming, water and food security closely follow climate variability and extremes. Thus, seasonal predictions of the onset and strength of monsoon rainfall are crucial for water resources as well as agricultural management and planning in India (Webster and Hoyos, 2004; Siddiq, 1999). During the monsoon season, usually from June to September, the Indian subcontinent receives $80-90 \%$ of the total annual rainfall in a sequence of rainy periods (monsoon bursts) and dry periods (monsoon breaks) of 10-20 days duration which stem, although they appear at first sight to be quite random, from intra seasonal oscillations (Webster and Hoyos, 2004).

As re-analysis data on atmospheric and oceanic state variable and fluxes but also climate model runs are globally available on resolutions ranging from $2.5^{\circ}$ to $1^{\circ}$ downscaling methods could help at least for generating historical monsoon rainfall estimates. Downscaling of precipitation can be achieved either dynamical or empirical (Wilby and Wilks, 1997). Within the dynamic approach, a "cascade" of dynamic atmospheric models run on a nested grid, where the finer resolved, regional models are driven by a Global Circulation Model (GCM). Regional models may be either regional climate models (Giorgi et al., 1999; Frei et al, 1998; Jacob et al., 2001; Bergstrom et al, 2001), which are hydrostatic models, or non hydrostatic mesoscale weather forecasting models such as the MM5 (Kunstmann and Jung, 2003). Dynamical downscaling yields satisfactory results when driven by GCMs in the assimilation mode. However, even when the same GCM forcing is used within a climate change scenario, regional climate models (RCMs) may produce significantly different results as recently shown by Jacob et al. (2001) in a comparative study for the Baltex area involving several different RCMs. 


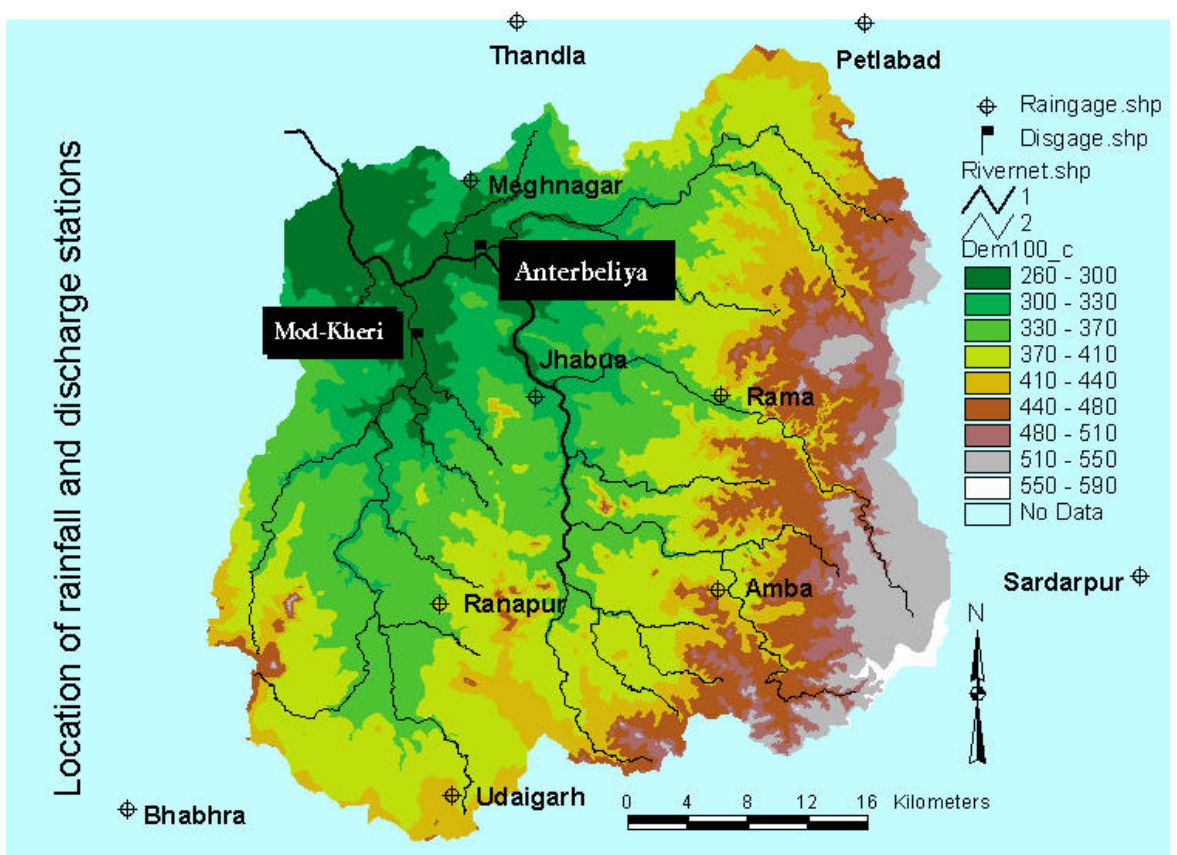

Fig. 1. Map view of the Anas catchment including the locations of the ten rain gauges. For location of the Anas catchment inside the Indian sub continent please check Figs. 5 or 6.

The idea of empirical downscaling is to establish a functional relationship between a globally available and reliable predictor variable such as geo-potential height of air pressure, air temperature or the sea surface temperature and locally observed meteorological variables such as precipitation or temperature in the area of interest. Crucial steps within the empirical approach are of course the selection of an appropriate predictor which explains the spatio-temporal variability of precipitation and the development of a predictorpredictant relation. Within empirical downscaling we distinguish methods which directly link the predictors to the surface variables in a basin of interest (e.g. Wilby et al., 1999), resampling methods (Wójcik and Buishand, 2003) or methods based on weather types. "Expanded Downscaling" (EDS) proposed by Bürger (2002) is a good example of a direct method. The principle is to predict catchment scale precipitation and temperature using a multivariate regression model with the geo-potential height, the temperature and the specific humidity of the GCM as predictors. The important constraint is that for the present climate, the observed spatial correlation structure of the surface variables has to be maintained.

Different methods for predicting inter seasonal variability of monsoon rainfall over the Indian subcontinent have been proposed over the years. Shukla and Mooley (1987) used the EL Nino Southern Oscillation (ENSO) to explain 30\% of the temporal monsoon variability over the Indian subcontinent. Early attempts to statistically link Eurasion snowfall in winter to the strength of the Indian monsoon did not yield convincing results (Dickson, 1984; Bamzai and Shukla, 1999). Harzallah and Sadourny (1999), Clark et al. (1999) and Clarke et al. (2000) proposed empirical schemes for linking monsoon rainfall and sea surface temperature anomalies. Gowarikar et al. (1991) developed a regional scale power regression models for rainfall forecasting in selected regions of India based on a time domain approach.

In the present study we want to focus on weather type related approaches. They were originally developed for Central Europe and are based on the insight that atmospheric circulation in the middle latitudes is strongly affected by the Coriolis force. This understanding was first reflected by the development of different sets of empirical circulation patterns or weather types that were found to cause in average always distinct weather in certain areas of central of southern Europe (Hess and Bresowsky, 1969; Maheras, 1988, 1989). Advancement of these ideas lead to the development of objective schemes for classification of circulation patterns that are statistically linked to precipitation in the basin of interest (Wilson et al, 1992; Bardossy et al., 1995; Wilby and Wigley, 2000; Conway and Jones, 1998; Özelkan et al., 1998).

The overall objective of the present study is to propose an empirical pressure based approach for precipitation downscaling for the Anas catchment in the North West of India. The present paper will shed light on the question to which extend objective pressure patterns, also named as circulation patterns (CP), that are classified by a fuzzy rule based classification scheme are suitable predictors to explain space time variability of monsoon rainfall in this region. Due to the 
Table 1. Statistical properties of daily rainfall data for various stations of Anas catchment during the monsoon season.

\begin{tabular}{lccccc}
\hline Station & $\begin{array}{c}\text { Average } \\
{[\mathrm{mm}]}\end{array}$ & $\begin{array}{c}\text { Maximum } \\
{[\mathrm{mm}]}\end{array}$ & $\begin{array}{c}\text { Standard deviation } \\
{[\mathrm{mm}]}\end{array}$ & $\begin{array}{c}\text { Rainfall prob. } \\
{[-]}\end{array}$ & $\begin{array}{c}\text { Average wet day amount } \\
{[\mathrm{mm}]}\end{array}$ \\
\hline Jhabua & 5.2 & 226.8 & 15.9 & 0.301 & 16.7 \\
Ranapur & 5.1 & 222.0 & 16.3 & 0.232 & 21.9 \\
Udaigarh & 5.3 & 207.2 & 14.8 & 0.340 & 15.7 \\
Amba & 5.6 & 200.0 & 16.7 & 0.256 & 21.7 \\
Rama & 6.1 & 318.0 & 19.6 & 0.258 & 23.7 \\
Meghnagar & 4.8 & 193.0 & 14.9 & 0.262 & 18.1 \\
Thandla & 5.7 & 225.8 & 17.6 & 0.316 & 18.2 \\
Bhabra & 5.2 & 210.0 & 14.7 & 0.313 & 19.6 \\
Sardarpur & 5.0 & 173.0 & 14.8 & 0.253 & 18.7 \\
Petlabad & 6.6 & 212.0 & 18.9 & 0.354 & \\
\hline
\end{tabular}

much weaker influence of the Coriolis force in the tropical latitudes it is not clear whether this approach, that has been successfully applied for precipitation downscaling in central and southern Europe (Stehlik and Bárdossy, 2002; Bárdossy and Filiz, 2005), is applicable at all. In a second companion paper (Zehe et al., 2006) we will present an analysis of monsoon rainfall observed in the Anas catchment, with special emphasis of the spatial and temporal (auto-) correlation structure, as well as rainfall simulations for the Anas catchment with a multivariate stochastic rainfall model that uses time series of CPs as large scale meteorological forcing.

The present paper is organised as follows. After presenting the study area and data base in Sect. 2, we will explain the CP classification methodology and the statistical methods we employ for testing whether circulation patterns are suitable predictors for catchment scale rainfall in the Anas catchment 3. After presenting the results in Sect. 4 we close with discussion and conclusions in Sect. 5.

\section{Research area and data records}

The Anas catchment is a head watershed of the Mahi river basin which falls under a semiarid climatic zone in North Western India. The catchment covers a geographical area of $1750 \mathrm{~km}^{2}$ with a mean altitude ranging from $280 \mathrm{~m}$ to $560 \mathrm{~m}$ (Fig. 1, compare Fig. 5 for the location of the Anas catchment in India). Daily rainfall data records for 10 stations were provided from the State Water Data Centre (SWDC) at Bhopal. Since $80-90 \%$ of the rainfall occurs during the monsoon season (June to October) rainfall data were only available for this period of the year. In a first step this data had to be digitized to allow a statistical analysis.

The average daily rainfall amount, the observed maximum, the standard deviation, and the average rainfall probability as well as the average rainfall amount at a wet day are listed in Table 1. Daily rainfall probabilities during the monsoon period range from 0.25 to 0.35 , the average rainfall amounts at a wet day are with 16 to $25 \mathrm{~mm}$ quite high. The total rainfall in the monsoon season which provides $90 \%$ of the total annual rainfall ranges from $350 \mathrm{~mm}$ to $1300 \mathrm{~mm}$ for dry to wet years, respectively. Although $1300 \mathrm{~mm}$ per year appears to be quite high the climate is nevertheless semiarid due to the high annual potential evaporation and the concentration of all the available precipitation on a period of 4 months. The rainfall station at Jhabua has the longest records ranging from 1957-1995. Records at Thandla range from 1964-1995 and the data records at the remaining stations range from 1985-1994. A more thorough analysis of the observed precipitation at the ten stations with respect to the average spatial correlation and the average autocorrelation is given in the companion paper (Zehe et al., 2006).

\section{Methodology}

\subsection{Classification of circulations patterns}

\subsubsection{Basic idea of the downscaling approach}

Stehlik and Bárdossy (2002) developed a methodology for generating spatio-temporal variable precipitation data using large scale daily pressure fields (simulated or observed) as well as local scale precipitation. The method consists of two main steps:

- An optimisation of fuzzy rules to classify pressure fields into circulation patterns (CPs), to explain the basin scale space-time variability of observed rainfall.

- A multivariate and stochastic generation of rainfall at different locations in the area of interest. The model is a conditional multivariate autoregressive rainfall model based on a transformed multivariate normal distribution. Rainfall is linked to the individual CP using conditional rainfall probability and amounts. The model accounts for the spatial covariance of daily precipitation is 
a function of the actual CP as well as of the day in the year. The annual cycles of the spatial covariance function and of the one day lag autocorrelation are described by means of a Fourier series.

Why do we select circulation patterns as predictor and not directly use the pressure data and additional predictors for predicting monsoon precipitation e.g. by employing expanded downscaling suggested by Bürger (2002)? As will become clear in the next section the CPs are able to discriminate the spatial locations where high or low pressure values are important for precipitation for the target area from those locations with no influence. This is a) an important insight and leads b) to an enormous gain in computation time, because a pressure pattern time series is a scalar predictor, that embeds the information on the spatial pressure pattern with it. As the focus of the present study is on the question whether pressure patterns are useful predictors for explaining space-time variability of precipitation in the Anas catchment, we omit further information on the multivariate rainfall model. Interested readers will find detailed information in Stehlik and Bárdossy (2002) as well as in the companion paper (Zehe et al., 2006).

\subsubsection{Definition of fuzzy rules and objective functions}

Input into $\mathrm{CP}$ classification is in principle daily geo-potential data from a selected level e.g. 700 or the $500 \mathrm{HPa}$ from the NCEP data set. In the first step the pressure data are transformed to standardised anomalies by subtracting the long term monthly average from the actual value at each node and dividing the resulting difference by the long term monthly standard deviation. The basic idea of assessing a CP or pressure pattern classification scheme is to identify a set of distinct locations in a spatial window where the configuration of pressure anomalies is on average associated with drier or wetter than average atmospheric conditions. Based on triangular fuzzy membership functions the daily anomalies at each location $(\mathrm{x}, \mathrm{y})$ are classified into the categories 1$)$ high, 2) medium high, 3) medium low, 4) low or 5) indifferent for the circulation pattern. The membership functions for the five categories are $\mathrm{v}=1$, low: $(-2.0,-1,-0.2)_{T} ; \mathrm{v}=2$, medium low: $(-1.4,-0.6,0)_{T} ; \mathrm{v}=3$, medium high: $(0,0.6$, $1.4)_{T} ; \mathrm{v}=4$, very high: $(0.2,1,2.0)_{T}$; and $\mathrm{v}=5$ indifferent, constant as 1 . Please note that the category "indifferent" is essential, as it allows separation of important locations from those which are not important.

Thus a circulation pattern, $\mathrm{CP}_{k}$, is fully characterised by an index vector $v(k)=\left\{v(1)^{(k)} \ldots v(n)^{(k)}\right\}$ that defines the locations of heights and depressions in the pressure window according to four categories. As a rule of thumb the anomalies at 10-12 locations in the windows is important, the rest is indifferent and is not stored, and a set of 10-12 circulation patterns is a good choice (Stehlik and Bárdossy, 2002). A pressure field for a given day is classified into a circulation pattern by calculating the degree of fulfilment (DOF) for each rule based on the membership values, $\mu$, of the actual pressure anomaly value at each node in the window and selecting the CP with the highest DOF (Bárdossy et. al., 2002).

To find out which locations are important as well as to optimise the CP classification scheme the selection of suitable objective functions is of highest importance. Following the approach of Stehlik and Bárdossy (2002) we defined:

$O_{1}=\sum_{i=1}^{S} \sqrt{\frac{1}{N_{d}} \sum_{t=1}^{N_{d}}\left(p(\mathrm{CP}(t))_{i}-\bar{p}\right)^{2}}$

where $S$ is number of stations with precipitation observations, $N_{d}$ is the number of days in the time series, $p(\mathrm{CP}(t))_{i}$ is the CP-conditional probability of a wet day at station $i, \bar{p}_{i}$ is the total average probability at station $i$. High values of $O_{1}$ indicate that the conditional rainfall probabilities of the CPs differs strongly from the average values i.e. represent drier or wetter than average meteorological conditions for the area. Stehlik and Bárdossy (2002) propose a second objective $\mathrm{O}_{2}$ based on the conditional precipitation amounts $z(\mathrm{CP})$ :

$O_{2}=\sum_{i=1}^{S} \frac{1}{N_{d}} \sum_{t=1}^{N_{d}}\left|\log \left(\frac{z_{p}(\mathrm{CP}(t))_{i}}{\bar{z}_{p, i}}\right)\right|$

where $\bar{z}_{i}$ is the overall average daily precipitation amount at station $i$. High values of $\mathrm{O}_{2}$ indicate that the conditional rainfall amount of a $\mathrm{CP}$ differ clearly from the average value. Within the optimization we used the sum of $O_{1}$ and $O_{2}$ as one possible objective function $O$. However, the log transformation in Eq. (2) puts a stronger weight on the small and average daily precipitation amounts as the logarithm is a very slowly increasing function. Alternatively, to assign higher weights to high and extreme daily precipitation values within the optimisation we defined an objective function $O_{2}^{\prime}$ based on the conditional precipitation amounts $\mathrm{z}(\mathrm{CP})$ :

$O_{2}^{\prime}=\sum_{i=1}^{S} \frac{1}{N_{d}} \sum_{t=1}^{N_{d}}\left|\left(\frac{z(\mathrm{CP}(t))_{i}}{\overline{z_{i}}}\right)^{b}\right|$

The total objective function, $O^{\prime}$, was again the sum of $O_{1}$ and $O_{2}^{\prime}$, with an exponent $b=1$ or 1.5 .

For optimisation we use simulated annealing (Press et al., 1992). The optimisation starts with an arbitrary set of fuzzy rules, classifies the pressure anomalies into a $\mathrm{CP}$ time series, determines $p(\mathrm{CP})$ and $z(\mathrm{CP})$ by frequency analysis and computes $O$ or $O^{\prime}$. Then a rule $k$ is randomly selected and one of the five categories, $v$, is randomly assigned to a randomly chosen location, $x_{i}, y_{i}$. A new classification is performed and $O$ or $O^{\prime}$ is calculated. If $O^{\prime}$ or $O^{\prime}$ is larger than the corresponding value of the old classification then the change is accepted. If not the change is accepted with a probability that decreases exponentially with decreasing annealing temperature. More details on the optimisation are given in Bárdossy et al. (2002). 

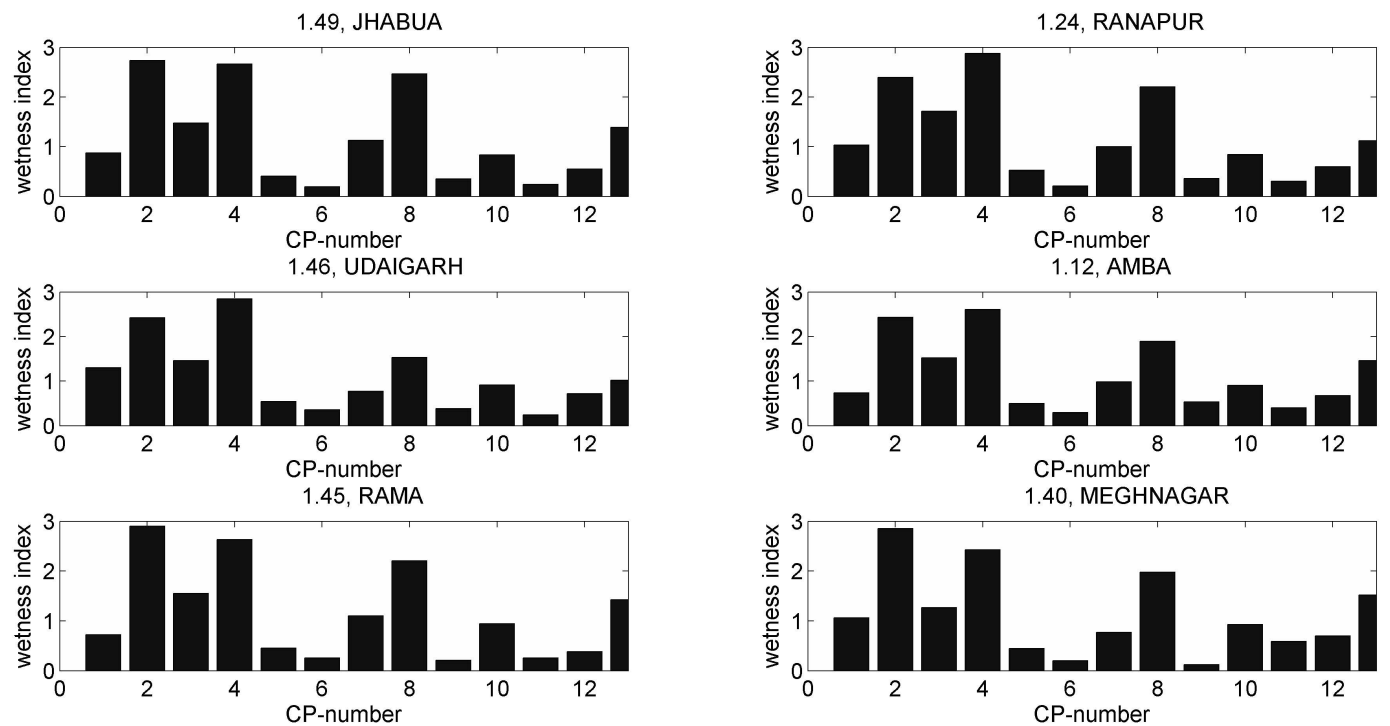

Fig. 2. Wetness index of the $500 \mathrm{HPa}$ CPs plotted for 6 rain gauges (defined according to Eqs. 4 and 5). Values larger than 1 indicate that the $\mathrm{CP}$ combines higher than average daily rainfall probabilities with higher than average conditional rainfall amounts. The figure header show the values of the objective function $\mathrm{O}_{2}$ (Eq. 1), the higher the values the better does the classification scheme separate between dry and wet CPs.
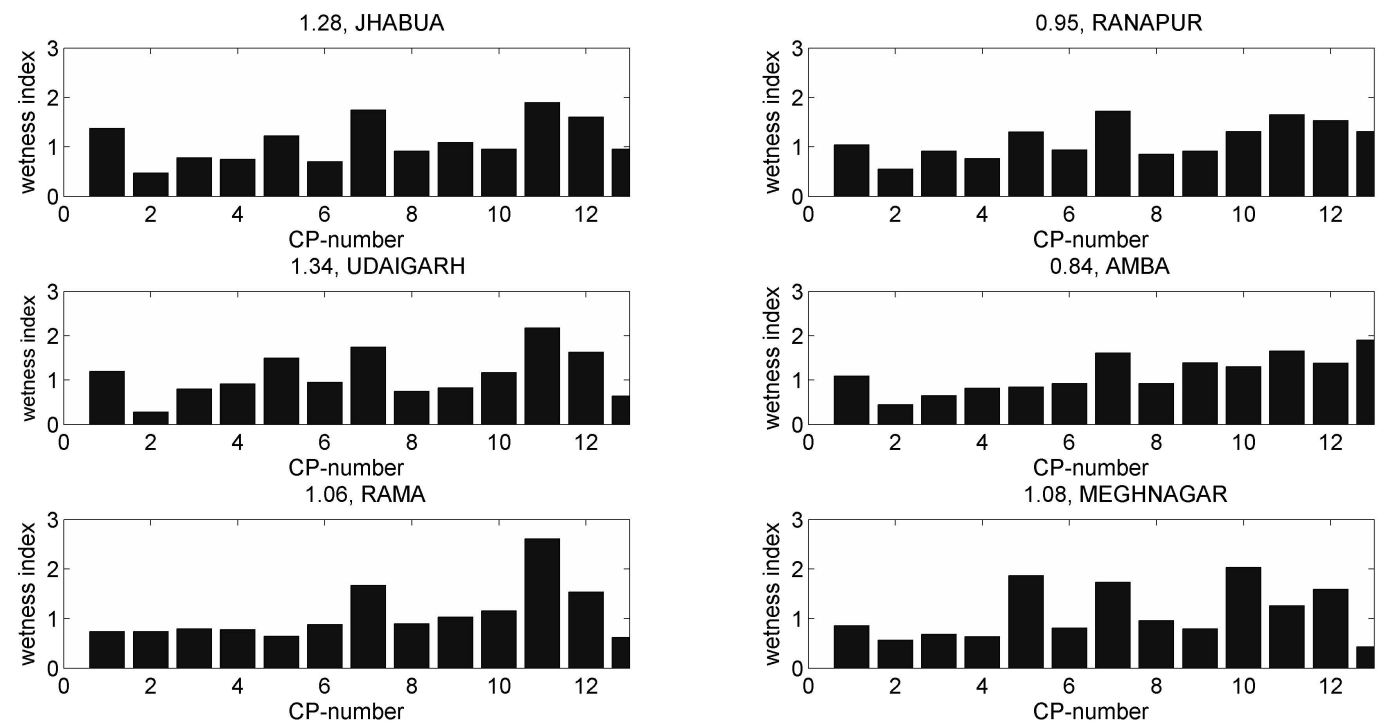

Fig. 3. Wetness index of the $500 \mathrm{HPa}$ CPs plotted for 6 rain gauges (defined according to Eqs. 4 and 5). Values larger than 1 indicate that the $\mathrm{CP}$ combines higher than average daily rainfall probabilities with higher than average conditional rainfall amounts. The figure headers show the values of the objective function $\mathrm{O}_{2}$ (Eq. 1).

\subsection{Quality assessment of the classification scheme}

Within the present study the following classification schemes were tested: a set of 10 or $12 \mathrm{CPs}$, classified either from the $500 \mathrm{HPa}$ pressure level or the $700 \mathrm{HPa}$ pressure level on a $2.5^{\circ}$ by $2.5^{\circ}$ grid. As spatial window we selected $5^{\circ} \mathrm{N} 40^{\circ} \mathrm{E}$ and $35^{\circ} \mathrm{N} 95^{\circ} \mathrm{E}$ which covers the Indian subcontinent as well as large parts of the Arabian Sea and the Gulf of Bengal. Furthermore, we compared the objective functions $O$ and $O^{\prime}$ for the exponents of $b=1$ and 1.5 respectively.

The objective function itself is a good criterion to compare the quality of different $\mathrm{CP}$ classification schemes. In addition we used the following measures: 

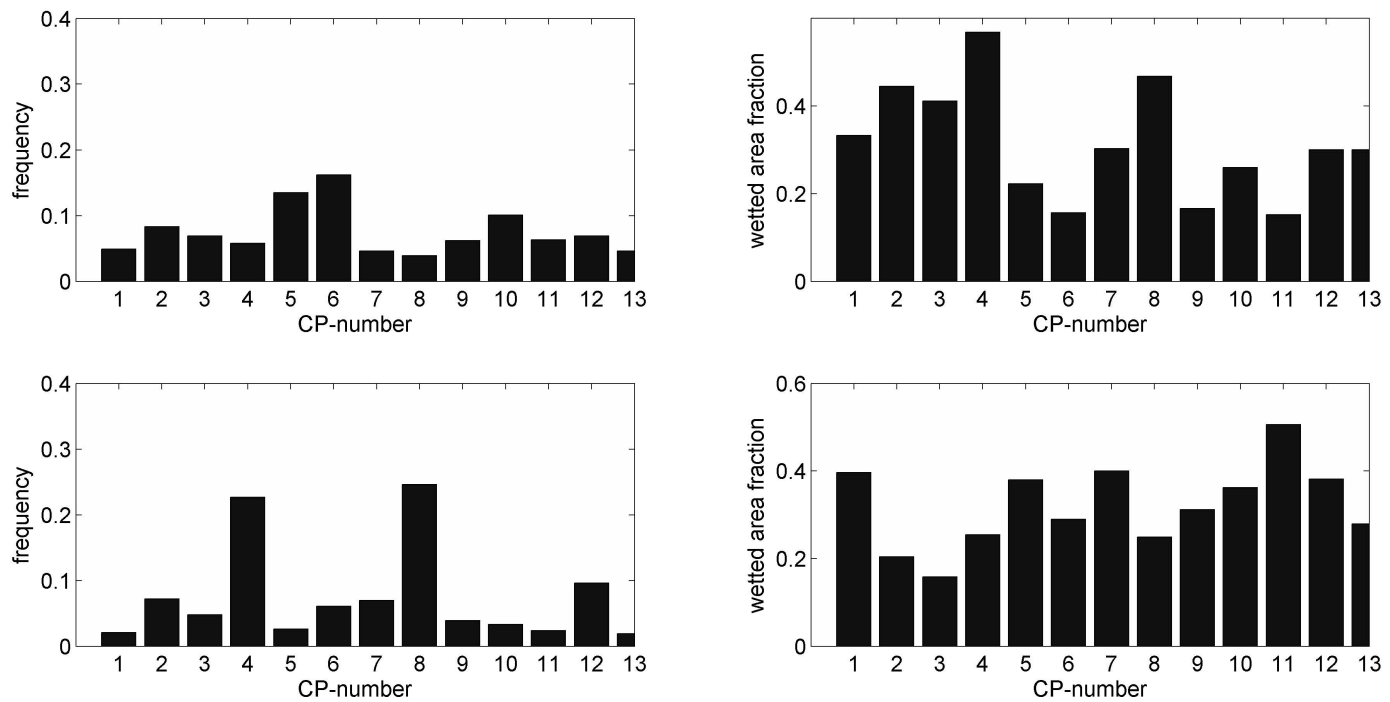

Fig. 4. Average CP frequency and average wetted area fraction, which denotes the average fraction of rain gauges where rainfall is observed, when weather is governed by a CP. The upper two panels denote the $500 \mathrm{HPa} \mathrm{CPs}$, the lower two the $700 \mathrm{HPa} \mathrm{CPs}$.

- The normalized conditional rainfall probability, $n_{p}$, defined as the conditional probability of precipitation at station $\mathrm{i}$ given the condition that the pressure at a day is classified into a given $\mathrm{CP}$ divided by the average precipitation probability, $p_{i}$, at this station. A strong deviation of $n_{p}$ from 1 indicates that the conditional rainfall probability of the $\mathrm{CP}$ is much higher or lower than the average.

$n_{p}=\frac{p_{i}(\mathrm{CP})}{\overline{p_{i}}}$

- The normalized conditional rainfall amount, $n_{z}$, defined as the conditional average precipitation amount on a wet day for a given $\mathrm{CP} z_{i}(\mathrm{CP})$ at station $i$ divided by the average precipitation amount, $z_{i}$, of a wet day at that station. A strong deviation of $n_{z}$ from 1 indicates that the conditional rainfall amount of the $\mathrm{CP}$ is much higher or lower than the average:

$$
n_{z}=\frac{z_{i}(\mathrm{CP})}{\overline{z_{i}}}
$$

The product of $n_{z}$ and $n_{p}$, named the wetness index, is a joint measure of whether the CP combines a higher/lower than average conditional rainfall probability with a higher/lower than average conditional rainfall amount.

Furthermore, to shed light on the significance of the CP conditional rainfall probabilities we selected the three wettest and the three driest CPs of the classification schemes with largest/smallest values for $n_{z}$ and $n_{p}$ obtained for the 700 and the $500 \mathrm{HPa}$ level respectively. Next we took 1000 bootstraps from the precipitation time series at each of the ten locations and computed the CP conditional rainfall probabilities for each bootstrap by frequency analysis for each of the selected CPs. The values were ranked in ascending order and we computed the fraction of bootstraps that were below the $\mathrm{CP}$ conditional probabilities. For the wet CPs the fraction of the bootstraps that are below has to be close to one to indicate that the significance of high precipitation probabilities is high. For the dry CPs it has to be the other way around: the number bootstraps that exceed the $\mathrm{CP}$ conditional rainfall probability has to be close to one to indicate that the classification is highly significant with respect to dry CPs.

Finally we computed the monthly frequencies of occurrence for each $\mathrm{CP}$ within the classification scheme and correlated them to the monthly rainfall totals as well as the monthly number of days observed at the 10 rain gauges. For optimising the CP classification scheme we selected the period from January 1985 to December 1994.

\section{Results}

\subsection{CP classification schemes for 700 and $500 \mathrm{HPa}$}

The first criteria for selecting a CP classification scheme are high values of the objective function. For both pressure levels a set of $12 \mathrm{CP}$ in combination with the objective function $O_{2}^{\prime}$ (Eq. 3) with an exponent $\mathrm{b}=1$ yielded the highest values for the total objective function $O$. Figure 1 and 2 present the wetness index of the circulation patterns for the rain gauges Jhabua, Ranapur, Udaigarh, Amba, Rama and Meghnagar, which are defined according to Eqs. (4) and (5). As the wetness indices for the remaining 4 rain gauges exhibit the same pattern, we omit the figures for reasons of brevity. Please 

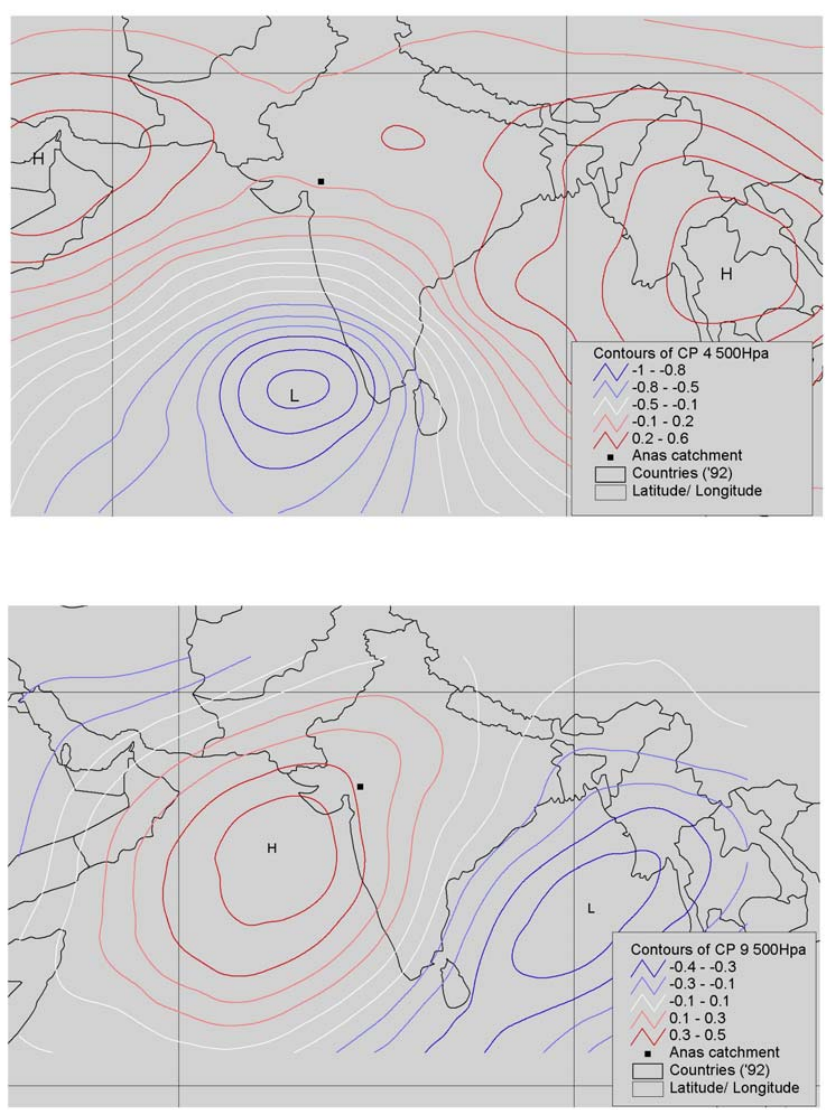

Fig. 5. Spatial distribution of $500 \mathrm{hPa}$ geo-potential height anomalies for the wet CP 4 (upper panel) and the dry CP 9 (lower panel), high values are shown in solid dark red lines while low pressure anomalies in solid blue lines.

note that values around one indicate that the $\mathrm{CP}$ is associated with average rainfall conditions during the monsoon season. Wetness indices higher/lower than 1 indicate that the CP represents drier or wetter than average weather conditions. The figure headers list, additionally to the station names, the values of the objective function $O_{1}$ (defined in Eq. 1). The higher the values the better the does the classification scheme separate between dry and wet weather situations.

The classification scheme for the $500 \mathrm{HPa}$ level separates dry from wet circulation patterns much more clearly than the classification scheme for the $700 \mathrm{HPa}$ level pressure level. CP2, CP4 and CP8 from the $500 \mathrm{HPa}$ level are associated in with atmospheric conditions that are more than twice as wet as the average. $\mathrm{CP} 9, \mathrm{CP} 11$ and $\mathrm{CP} 6$ result in much drier than average conditions in the Anas catchment. For the $700 \mathrm{HPa}$ level CP11, CP12 and CP7 yield wet conditions, although their wetness index is smaller as in the case of the $500 \mathrm{HPa}$ level. CP2, CP3 and CP6 represent on average dry meteorological conditions.

Figure 4 presents the average CP frequency and average wetted area fraction, which denotes the average fraction of
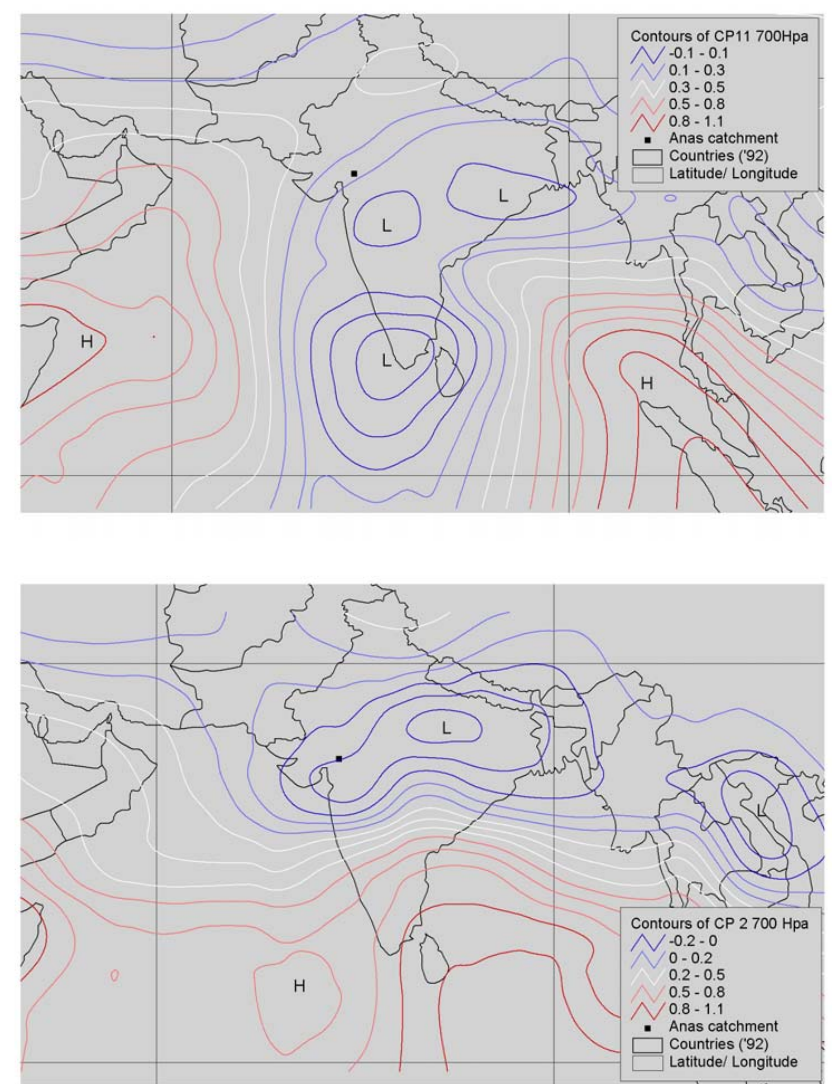

Fig. 6. Spatial distribution of $700 \mathrm{hPa}$ geo-potential height anomalies for the wet CP 11 (upper panel) and the dry CP 2 (lower panel), high values are shown in solid dark red lines while low pressure anomalies in solid blue lines.

rain gauges where rainfall is observed when weather is governed by a CP. The upper two panels belong to the $500 \mathrm{HPa}$ $\mathrm{CPs}$, the lower two to the $700 \mathrm{HPa} \mathrm{CPs}$. The wet $\mathrm{CP} 2$ for the $500 \mathrm{HPa}$ level yields an average precipitation coverage of almost $60 \%$ of the rain gauges, the dry $\mathrm{CP} 9$ causes in a coverage of only $18 \%$. In case of the $700 \mathrm{HPa}$ the wet/dry CPs are also associated with a larger/smaller fraction of the catchment by precipitation, but the differences are less pronounced. Due to the more even occurrence frequencies of the CPs of the $500 \mathrm{HPa}$ level the classification scheme has a higher entropy than the $700 \mathrm{HPa}$ classification scheme. In the $700 \mathrm{HPa}$ level CP4 and CP8, which are both associated with average rainfall conditions, dominate almost $50 \%$ of the time.

Figure 5 illustrates the average locations of the highs and depressions associated with the wettest $\mathrm{CP} 4$ and the dry CP9 in the $500 \mathrm{HPa}$ level, as well as the location of the Anas catchment in India. Due to a depression located over the Indian Ocean and a strong anticyclone with kernel over the Arabian Peninsula CP4 causes a streaming of moist air masses from the southern Indian Ocean to North-Western India. The dry CP9 forms a "bridge" of two anticyclones rang- 
Table 2. Frequency of bootstraps who's CP conditional rainfall probability was below the ones calculated for the original time series for the wet circulation patterns CP11 CP7 and CP12, as well as for the dry ones CP8, CP2 and CP3 in the 500 HPa level. In case of the wet CP the fraction is an estimator for the significance of the $\mathrm{CP}$ conditional rainfall probability, for the dry CPs one minus the fraction estimates the significance level.

\begin{tabular}{ccccccccccc}
\hline CP & 1 & 2 & 3 & 4 & 5 & 6 & 7 & 8 & 9 & 10 \\
\hline CP 4 & 1.000 & 1.000 & 1.000 & 1.000 & 1.000 & 1.000 & 1.000 & 1.000 & 1.000 & 1.000 \\
CP 8 & 1.000 & 0.999 & 0.999 & 0.978 & 1.000 & 0.999 & 1.000 & 0.992 & 0.985 & 1.000 \\
CP 2 & 0.998 & 1.000 & 1.000 & 1.000 & 1.000 & 1.000 & 1.000 & 1.000 & 0.999 & 0.998 \\
CP11 & 0.000 & 0.009 & 0.000 & 0.001 & 0.000 & 0.063 & 0.000 & 0.002 & 0.000 & 0.002 \\
CP 6 & 0.000 & 0.000 & 0.000 & 0.000 & 0.000 & 0.000 & 0.000 & 0.000 & 0.000 & 0.000 \\
CP 9 & 0.001 & 0.016 & 0.001 & 0.042 & 0.011 & 0.000 & 0.000 & 0.024 & 0.002 & 0.000 \\
\hline
\end{tabular}

1 = Jhabua, 2 = Ranapur, $3=$ Udaigarh, $4=$ Amba, $5=$ Rama, $6=$ Meghnagar, $7=$ Thandla, $8=$ Bhabra, $9=$ Sardapur, $10=$ Petlabad

Table 3. Frequency of bootstraps who's CP conditional rainfall probability was below the ones calculated for the original time series for the wet circulation patterns CP11 CP7 and CP12, as well as for the dry ones CP6, CP2 and CP3 in the $700 \mathrm{HPa}$ level. In case of the wet CP the fraction is an estimator for the significance of the $\mathrm{CP}$ conditional rainfall probability, for the dry CPs one minus the fraction estimates the significance level.

\begin{tabular}{lcccccccccc}
\hline CP & 1 & 2 & 3 & 4 & 5 & 6 & 7 & 8 & 9 & 10 \\
\hline CP11 & 1.000 & 0.948 & 0.987 & 0.944 & 1.000 & 0.999 & 1.000 & 0.996 & 1.000 & 1.000 \\
CP 7 & 0.998 & 0.993 & 0.999 & 0.993 & 0.989 & 0.996 & 0.983 & 0.990 & 1.000 & 0.985 \\
CP12 & 0.993 & 0.997 & 1.000 & 0.914 & 0.980 & 0.993 & 0.994 & 0.998 & 1.000 & 0.892 \\
CP 6 & 0.051 & 0.015 & 0.004 & 0.054 & 0.074 & 0.041 & 0.038 & 0.008 & 0.052 & 0.054 \\
CP 2 & 0.005 & 0.048 & 0.000 & 0.060 & 0.070 & 0.054 & 0.085 & 0.011 & 0.001 & 0.095 \\
CP 3 & 0.002 & 0.034 & 0.000 & 0.001 & 0.005 & 0.055 & 0.028 & 0.002 & 0.068 & 0.001 \\
\hline
\end{tabular}

1 = Jhabua, 2 = Ranapur, $3=$ Udaigarh, $4=$ Amba, $5=$ Rama, $6=$ Meghnagar, $7=$ Thandla, $8=$ Bhabra, $9=$ Sardapur, $10=$ Petlabad

ing from the Indian Ocean to Mongolia which causes dry and hot weather conditions. For comparison Fig. 6 shows the average locations of the highs and depressions associated with the wettest CP11 and the dry CP2 in the $700 \mathrm{HPa}$ level. $\mathrm{CP} 11$ in the $700 \mathrm{HPa}$ appears with a pronounced depression with kernel in South West India similar to the wet CP4 in the $500 \mathrm{HPa}$ level. CP2 is quite different: a strong depression over north-eastern India combined with an anticyclone located South-West from the Malabar Coast is expected to lead moist air from the Arabian Sea to central India. However, the Anas catchment should receive dry air from the NorthEastern part of India, that has to pass the mid-mountain barrier at the East of the catchment. Hence, it is associated with drier weather conditions.

\subsection{Significance $\mathrm{CP}$ conditional rainfall probabilities}

Table 2 lists the fraction of the bootstraps whose CP conditional rainfall probability was below the values calculated for the original time series for the wet circulation patterns CP11 $\mathrm{CP} 7$ and CP12, as well as for the dry ones CP8, CP2 and CP3 in the $500 \mathrm{HPa}$ level. In the case of a wet $\mathrm{CP}$ this fraction is an estimator for the significance of the $\mathrm{CP}$ conditional rainfall probability. For dry CPs the significance level is obtained by subtracting the fraction from one. The significance of the conditional rainfall probabilities for the wet as well as for the dry CPs is for all rain gauges larger than $95 \%$. As can be seen in Table 3 the significance of the conditional rainfall probabilities for the wet CPs CP11, CP12 and CP 7 in the $700 \mathrm{HPa}$ is similarly high as for the $500 \mathrm{HPa}$ scheme. The significance of the dry CPs CP2, CP3, and CP6 is a little weaker as for the $500 \mathrm{HPa}$ scheme

Table 4 shows additionally the correlation between the monthly frequency of the wet and dry CPs in the $500 \mathrm{HPa}$ level with the monthly number of rainy days observed at the different rain gauges during the Monsoon season. For the wettest CPs CP 2 and CP 4 the correlations range between 0.35 and 0.45. Consistently, the frequencies of the driest CPs show a clearly negative correlation with the monthly number of rainy days. For the $700 \mathrm{Hpa}$ classification scheme we observe the same behaviour: positive/negative correlations between the frequencies of wet/dry CPs and the monthly number of rainy days, however, with smaller values. A t-test showed that all correlations are significant at the $95 \%$ level. 
Table 4. Correlation between the monthly frequency of the wet and dry CPs in the $500 \mathrm{HPa}$ level with the monthly number of rainy days at the different rain gauges during the Monsoon season.

\begin{tabular}{lrrrrrrrrrr}
\hline $\mathrm{CP}$ & 1 & 2 & 3 & 4 & 5 & 6 & 7 & 8 & 9 & 10 \\
\hline $\mathrm{CP} 2$ & 0.329 & 0.257 & 0.330 & 0.402 & 0.250 & 0.349 & 0.238 & 0.337 & 0.374 & 0.263 \\
$\mathrm{CP} 4$ & 0.349 & 0.400 & 0.374 & 0.359 & 0.415 & 0.358 & 0.401 & 0.313 & 0.313 & 0.456 \\
$\mathrm{CP} 8$ & 0.156 & 0.168 & 0.162 & 0.165 & 0.214 & 0.156 & 0.184 & 0.147 & 0.169 & 0.200 \\
$\mathrm{CP} 6$ & -0.223 & -0.313 & -0.361 & -0.382 & -0.301 & -0.405 & -0.399 & -0.319 & -0.332 & -0.399 \\
$\mathrm{CP} 9$ & -0.355 & -0.332 & -0.318 & -0.270 & -0.347 & -0.376 & -0.372 & -0.310 & -0.370 & -0.372 \\
$\mathrm{CP} 11$ & -0.286 & -0.246 & -0.232 & -0.258 & -0.251 & -0.186 & -0.219 & -0.132 & -0.228 & -0.201 \\
\hline
\end{tabular}

1 = Jhabua, 2 = Ranapur, $3=$ Udaigarh, 4 = Amba, $5=$ Rama, $6=$ Meghnagar, $7=$ Thandla, $8=$ Bhabra, $9=$ Sardapur, $10=$ Petlabad

Table 5. Correlation between the monthly frequency of the wet and dry CPs in the $700 \mathrm{HPa}$ level with the monthly number of rainy days at the different rain gauges during the Monsoon season.

\begin{tabular}{lrrrrrrrrrr}
\hline $\mathrm{CP}$ & 1 & 2 & 3 & 4 & 5 & 6 & 7 & 8 & 9 & 10 \\
\hline $\mathrm{CP} 2$ & -0.295 & -0.322 & -0.338 & -0.233 & -0.260 & -0.225 & -0.296 & -0.307 & -0.401 & -0.339 \\
$\mathrm{CP} 3$ & -0.243 & -0.266 & -0.290 & -0.281 & -0.306 & -0.265 & -0.291 & -0.242 & -0.276 & -0.300 \\
$\mathrm{CP} 6$ & -0.153 & -0.261 & -0.296 & -0.113 & -0.163 & -0.136 & -0.195 & -0.252 & -0.197 & -0.249 \\
$\mathrm{CP} 7$ & 0.169 & 0.217 & 0.260 & 0.218 & 0.118 & 0.247 & 0.208 & 0.241 & 0.284 & 0.275 \\
$\mathrm{CP} 11$ & 0.241 & 0.366 & 0.214 & 0.284 & 0.342 & 0.276 & 0.319 & 0.274 & 0.271 & 0.242 \\
$\mathrm{CP} 12$ & 0.275 & 0.311 & 0.400 & 0.256 & 0.377 & 0.363 & 0.327 & 0.336 & 0.367 & 0.270 \\
\hline
\end{tabular}

1 = Jhabua, 2 = Ranapur, $3=$ Udaigarh, $4=$ Amba, $5=$ Rama, $6=$ Meghnagar, $7=$ Thandla, $8=$ Bhabra, $9=$ Sardapur, $10=$ Petlabad

\section{Discussion and conclusions}

The presented results give clear evidence that objective circulation classified patterns especially from the $500 \mathrm{HPa}$ level are suitable to explain the spatio-temporal variability of monsoon rainfall within the Anas catchment. The CP conditional rainfall probabilities of the wettest and the driest CPs are highly significant. Furthermore, $30 \%$ of the variation of the monthly number of rainy days at all stations may be explained by the occurrence frequency of the three wettest CPs of the $500 \mathrm{HPa}$ level. Shukla and Mooley (1987) found a similar strong relation between the EL Nino Southern Oscillation (ENSO) and the temporal monsoon variability over the India.

Near to the Equator one would of course expect the CPs from $700 \mathrm{HPa}$ level, which are in average located at a height of $3000 \mathrm{~m}$, to have a stronger influence. However, as the Anas catchment is located approximately $23^{\circ}$ north, the Coriolis parameter is of order 0.4. Although this is only half as large as in the mid-latitudes, the influence of the Coriolis force seems still large enough that the CPs from the $500 \mathrm{HPa}$ level are the better predictors.

The overall objective of this study was to give evidence that objectively classified pressure patterns are suitable predictors for monsoon rainfall in North West India, despite the low influence of the Coriolis force. We may state that this goal has been successfully achieved. However, the identification of a suitable predictor is only the first essential step towards modelling monsoon precipitation by means of empirical downscaling. The next essential step, which is addressed in the companion paper (Zehe et al., 2006), is to establish a suitable predictive relationship between the predictors and the rainfall in the Anas catchment. This is achieved by means of a multivariate stochastic model originally proposed by Stehlik and Bárdossy (2002) which uses CP time series as large scale meteorological forcing. Either pressure fields from reanalysis data or from climate model runs maybe be classified into such a $\mathrm{CP}$ time series. The proposed approach may be used for generating historical rainfall time series for e.g. for water resources planning as well as for questions of climate impact assessment. Interested readers shall therefore refer to Zehe et al. (2006).

Edited by: M. Sivapalan

\section{References}

Bárdossy, A. and Filiz, F.: Identification of flood producing atmospheric circulation patterns, J. Hydrol., 313, 48-57, 2005.

Bárdossy, A., Stehlik, J., and Caspary, H.-J.: Automated objective classification of daily circulation patterns for rainfall and temperature downscaling based on optimised fuzzy rules, Clim. Res., 23, 11-22, 2002.

Bárdossy, A., Stehlik, J., and Caspary, H.-J.: Generating of areal precipitation series in the upper Neckar catchment, Phys. Chem. Earth (B), 26, 683-687, 2001. 
Bárdossy, A., Duckstein, L., and Bogárdi, I.: Fuzzy rule based classification of atmospheric circulation patterns, Int. J. Climatol., 15, 1087-1097, 1995.

Bamzai, A. S. and Shukla, J.: Relation between Eurasian snow cover, snow depth and the Indian summer monsoon: An observational study, J. Clim., 12, 3117-3132, 1999.

Bogardy, I., Matyasovszky, I., Bardossy, A., and Duckstein, L.: A hydro-climatological model of areal droughts, J. Hydrol., 153, 245-264, 1994.

Bergstrom, S. Carlson, B., Gardekin, M., Lindstrom, G., Peterson, A., and Rummukainen, M.: Climate change impacts on Hydrology in Sweden - assessment by global circulation models, dynamical downscaling and hydrological modelling, Clim. Res., 16, 101-112, 2001.

Bürger, G.: Selected precipitation scenarios across Europe, J. Hydrol., 262, 99-110, 2002.

Clark, C. O, Cole, J. E., and Webster, P. J.: Indian ocean SST and Indian summer rainfall: Predictive relationships and their decadal variability, J. Clim., 13, 2503-2519, 1999.

Clarke, M. P., Hay, L. E., McCabe, G. J., Leavesley, G. H., Serreze, M. C., Wilby, R. L.: The use of weather and climate information in management of water resources in the western United States, Proceedings of the Special Conference on Climate Variability and Water Resources, NOAA, Boulder, USA, 2001.

Conway, D. and Jones, P. D.: The use of weather types and airflow indices for GCM downscaling, J. Hydrol., 213, 348-361, 1998.

Dickson, R. R.: Eurasion snow cover versus Indian monsoon rainfall. An extension of the Hahn - Shukla results, J. Clim. Appl. Meteor., 23, 171-173, 1984.

Frei, C., Schar, C., Luthi, D., and Davies, H. C.: Heavy precipitation processes in a warmer climate, Geophys. Res. Lett., 25, 14311434, 1998

Giorgi, F. , Mearns, L. O., Shields, C., and McDaniel, L.: Regional nested model simulations of present and $2 \mathrm{x} \mathrm{CO}_{2}$ climate over the central plains of the US, Clim. Change, 40, 457-493, 1999.

Gowarikar, V., Thapliyal, V., Kulshrestha, S. M., Mandal, G. S., Sen Roy, N., Sikka, D. R.: A power regression model for long range forecast of south-west monsoon rainfall over India, Mausam, 42, 125-130, 1991.

Harzallah, A. and Sadourny, R.: Observed lead lag relationships between Indian summer monsoon and some meteorological variables, Clim. Dyn., 13, 635-648, 1999.

Hess, P. and Brezowsky, H.: Katalog der Großwetterlagen Europas. 2. neu bearb. u. erg. Aufl., Berichte des Deutschen Wetterdienstes 113; Selbstverlag des DWD, Offenbach a.M., Deutschland, 1969.

Jacob, D., van den Hurk, J. J. M., Andrae, U., Elgered, G., Fortelius, C. Graham, L. P., Jackson, S, D., Karstens, U., Köpken, Chr. Lindau, R. Podzun, R., Rockel, B. Rubel, F. Sass, B. H., Smith, R. N. B., and Yang, X.: A comprehensive model inter-comparison study investigating the water budget during the BALTEX-PIDCAP period, Meteorol. Atmos. Phys., 77, 19-43, 2001.
Kunstmann, H. and Jung, G.: Investigation of feedback mechanisms between soil moisture, landuse and precipitation in West Africa, Water Resources System, Water Availiability and Global Change, IAHS Publications 280, 159-159, 2003.

Maheras, P.: The synoptic weather types and objective delimitation of the winter period in Greece, Weather, 43, 2, 40-45, 1988.

Maheras, P.: Delimitation of the Summer-dry period in Greece according to the frequency of weather-types, Theor. Appl. Climatol., 39, 171-176, 1989.

MoE India: India's National Communication of the UNFCCC, Ministry of Environment and Forests, Government of India, Delhi, 2004.

Press, W. H., Teukolsky, S. A., Vetterling, W. T., and Flannery, B. P.: Numerical Recipes in FORTRAN: The Art of Scientific Computing, Cambridge University Press, 1992.

Özelkan, E., Galambosi, L., Duckstein, L., and Bárdossy, A.: A multi-objective fuzzy classification of large scale circulation patterns for precipitation modeling, Appl. Math. Comp., 91, 127$142,1998$.

Shukla, J. and Mooley, D. A.: Empirical prediction pf the summer monsoon rainfall over India, Mon. Wea. Rev., 115, 695-703, 1987.

Siddiq, E. A.: Rainfall prediction for rice growing areas, in: Rice in a variable climate, edited by: Abrol, Y. P. and Gadgil, S., APC Publication Delhi, pp. 107-123, 1999.

Stehlik, J. and Bardossy, A.: Multivariate stochastic downscaling model for generating daily Rainfall series based on atmospheric circulation, J. Hydrol., 256, 120-141, 2002.

Webster, P. J. and Hoyos, C.: Prediction of monsoon rainfall and river discharge on 15-30 day time scales, Bull. Amer. Meteor. Soc., 85, 1745-1767, 2004.

Wójcik, R. and Buishand, T. A.: Simulation of 6-hourly rainfall and temperature by two resampling schemes, J. Hydrol. 273, 14, 69-80, 2003.

Wilby, R. L. and Wigley, T. M. L.: Precipitation predictors for downscaling - observed and general circulation model relationships, Int. J. Climatol., 20, 641-661, 2000.

Wilby, R. L,. Hay, L. E., and Leavesly, G. H.: A comparsion of downscaled and raw GCM output: implications for climate change scenarios in the San Juan River basin, Colorado, J. Hydrol., 225, 67-91, 1999.

Wilby, R. L. and Wigley, T. M. L.: Downscaling general circulation model output: a review of methods and limitations, Prog. Phys. Geogr., 21, 530-548, 1997.

Wilson, L. L., Lettenmaier, D. P., and Skyllingstaed, E.: A multiple stochastic daily precipitation model conditional on large scale circulation patterns, J. Geophys. Res., 97, 2791-2801, 1992. 